\title{
A sequência pré-glacial do Grupo Macaúbas na área-tipo e o registro da abertura do rifte Araçuaí
}

\author{
Maximiliano Martins ${ }^{1}$, Joachim Karfunkel ${ }^{1}$, Carlos Maurício Noce ${ }^{1}$, Marly Babinski², \\ Antônio Carlos Pedrosa-Soares ${ }^{1}$, Alcides Nóbrega Sial \& Dunyi Liu ${ }^{4}$
}

\begin{abstract}
Resumo No presente trabalho são apresentados os resultados sobre evolução sedimentar e a estratigrafia redefinida para a fase rifte do Grupo Macaúbas e Supergrupo Espinhaço, na região do Orógeno Araçuaí balizada pela bacia hidrográfica do rio Macaúbas (MG). O Supergrupo Espinhaço é formado unicamente pelos sedimentos eólicos da Formação Resplandecente, assentando-se diretamente sobre o embasamento Arqueano/ Paleoproterozóico. A formação basal do Grupo Macaúbas - Fm. Matão - é parcialmente limitada por superfícies erosivas descontínuas de primeira ordem de grandeza, materializando um grande lapso de tempo entre os ciclos "Espinhaço" e "Macaúbas". Esta formação possui grãos de zircão detríticos com idade de ca. 1,16 Ga (U-Pb SHRIMP), limitando sua idade máxima de sedimentação. A Formação Duas Barras caracteriza os sedimentos marinhos costeiros em um estágio mais avançado de abertura do Rifte Araçuaí, possivelmente com contribuições tanto do craton São Francisco quanto do craton do Congo.
\end{abstract}

Palavras-chave: Rio Macaúbas, Supergrupo Espinhaço, Grupo Macaúbas, estratigrafia, evolução.

\begin{abstract}
The Macaúbas Group on the Macaúbas river basin (MG) and the register of the rifting phase of the Araçuai Basin. This paper presents the sedimentary evolution and a new stratigraphy suggested by the rift phase of the Macaúbas Group and Espinhaço Supergroup of the Araçuaí orogen, located at the Macaúbas River basin (Minas Gerais State). The Espinhaço Supergroup is formed by the Resplandecente Formation (aeolian depositional system). Paleocurrent data indicate that the source area of the Resplandecente Formation was the São Francisco craton region. The Macaúbas Group represents the precursor basin of the Neoproterozoic Araçuaí orogen and the pre-glacial sedimentation is represented by two units: Matão and Duas Barras formations. The basal unit of the Macaúbas Group - Matão Formation - is formed by lower breccia and conglomerates and represents deposition under unstable conditions, covered by a thick package of fine sandstone (shallow marine transgressive sediments). Detrital zircon grains dated at ca. $1.16 \mathrm{Ga}$ (U-Pb SHRIMP) limit the maximum age of the Matão Formation. Duas Barras Formation represents pre-glacial marine sediments. Both São Francisco craton and Congo craton could be the source for Duas Barras sediments.
\end{abstract}

Keywords: Macaúbas river, Espinhaço Supergroup, Macaúbas Group, stratigraphy, evolution.

INTRODUÇÃO A Serra do Espinhaço Setentrional em Minas Gerais é separada da parcela meridional por uma descontinuidade de aproximadamente $50 \mathrm{~km}$ na altura do paralelo $17^{\circ} 30^{\prime} \mathrm{S}$. Inicia-se ao sul da cidade de Itacambira, onde os metassedimentos do Supergrupo Espinhaço formam um cordão de serras em arco, quase sempre contínuos, com concavidade voltada para o norte. Esta faixa é interpretada como o núcleo de uma grande estrutura anticlinória de direção N-S e caimento de eixo para sul (Anticlinal de Itacambira, Karfunkel \& Karfunkel 1977), cujo flanco oriental prolonga-se ininterruptamente até o estado da Bahia (Fig. 1).

A bacia hidrográfica do Rio Macaúbas abrange cerca de $1600 \mathrm{~km}^{2}$ de área, inserindo-se no compartimento externo do Orógeno Araçuaí, ocupando o flanco ocidental da estrutura anticlinória de Itacambira, no do- mínio dos metassedimentos do Supergrupo Espinhaço, a leste, e do Grupo Macaúbas em quase sua totalidade (Fig. 1). Esta região representa o locus typicus da Formação "Macahúbas" de Moraes (1928, 1932), sendo parte integrante dos levantamentos regionais de Karfunkel \& Karfunkel (1977) e de Noce (1997).

A luz do conhecimento atual, o Supergrupo Espinhaço e o Grupo Macaúbas representam dois períodos superpostos de rifteamento que atingiram o Cráton São Francisco-Congo ao longo do Proterozóico, constituindo unidades geotectônicas importantes no arcabouço do Orógeno Neoproterozóico Araçuaí - Oeste Congo.

$\mathrm{O}$ mapeamento geológico da área compreendida pela bacia do Rio Macaúbas em escala 1:50.000 (Martins 2006), com atenção especial para as unidades pré-cambrianas, foi parcialmente apoiado por dados

1 - IGC-CPMTC, Universidade Federal de Minas Gerais, Belo Horizonte (MG), Brasil. E-mails: maximilianomartins@yahoo.com.br; jokarfun@igc.ufmg.br; noce@igc.ufmg.br; pedrosa@pesquisador.cnpq.br

2 - IG-CPG, Universidade de São Paulo, São Paulo (SP), Brasil. E-mail: babinski@usp.br

3 - NEG-LABISE, Universidade Federal de Pernambuco, Recife (PE), Brasil. E-mail: sial@ufpe.br

4 - Beijing SHRIMP Laboratory, Chinese Academy of Geological Sciences, 100037 Beijing, China 
geocronológicos. Como resultado, foram redefinidas e reconhecidas novas unidades litoestratigráficas para o Supergrupo Espinhaço e, principalmente, para a seqüência pré-glacial do Grupo Macaúbas nesta região. Os dados aqui apresentados possibilitam tecer novas considerações sobre o desenvolvimento das bacias "Espinhaço" e "Macaúbas", possuindo ainda implicações relevantes para a evolução do Orógeno Araçuaí.

CONTEXTO GEOLÓGICO REGIONAL O Orógeno Araçuaí (Pedrosa-Soares et al. 2001) localiza-se na margem sudeste do Cráton do São Francisco, orientado aproximadamente na direção $\mathrm{N}-\mathrm{S}$, com vergência para oeste e transporte tectônico para o cráton (Almeida 1977). No domínio ocidental do orógeno, próximo ao contato com a borda do cráton e macroregião onde se encontra a bacia hidrográfica do Rio Macaúbas, as principais unidades litoestratigráficas são representadas pelo embasamento, de idade arqueana a paleoproterozóica, os metassedimentos paleo/mesoproterozóicos do Supergrupo Espinhaço, o Supergrupo São Francisco grupos Macaúbas e Bambuí, Neoproterozóico e unidades fanerozóicas (Uhlein et al. 1995). O metamorfismo nesta zona é do fácies xisto verde baixo (Fig. 1).

As reconstruções do Gondwana Ocidental advogam que o Cráton do São Francisco, no Brasil, e o Cráton do Congo, na África, formaram uma massa continental única desde o final do Paleoproterozóico até a abertura do proto-oceano do Atlântico Sul, no Cretáceo (Pedrosa-Soares et al. 2001). Esta abertura oceânica separou o Orógeno Araçuaí-Oeste Congo, que havia se desenvolvido durante a Orogênese Brasiliana-PanAfricana em uma reentrância do bloco continental São Francisco-Congo (Alkmim et al. 2006).

O Supergrupo Espinhaço representa o primeiro evento de rifteamento que afetou o Cráton São FranciscoCongo por volta de 1,75 Ga (Dussin \& Dussin 1995). O Supergrupo Espinhaço compõe e sustenta a serra homônima e se estende por aproximadamente $1200 \mathrm{~km}$ segundo o meridiano, distribuindo-se ao longo do Orógeno Araçuaí ou como cobertura sobre o atual Cráton do São Francisco. É formado por associações vulcano-sedimentares na base, sobreposto por um espesso pacote de sedimentos siliciclásticos em direção ao topo, com porções localizadas de sedimentos carbonáticos. É interpretado como uma bacia ensiálica do tipo rift-sinéclise, nucleada ao final do Paleoproterozóico, com desenvolvimento bacinal policíclico descontínuo ao longo do Meso e talvez do Neoproterozóico (Danderfer \& Dardenne 2002, Martins-Neto 2007).

$\mathrm{O}$ segundo período de rifteamento iniciou-se ao redor de 1,0 Ga e gerou as condições necessárias para a deposição do Grupo Macaúbas no Orógeno Araçuaí, e de seu correlato africano, representado pela porção basal e intermediária do Supergrupo Oeste Congo, no cinturão metamórfico homônimo (Pedrosa-Soares et al. 2001, Tack et al. 2001). Durante este período, o sistema de falhas do Estateriano foi reativado (Uhlein et al. 1995), concomitantemente com um evento glacial que cobriu parte da área cratônica (Karfunkel \& Hoppe 1988).

O Grupo Macaúbas registra um evento tafrogê-

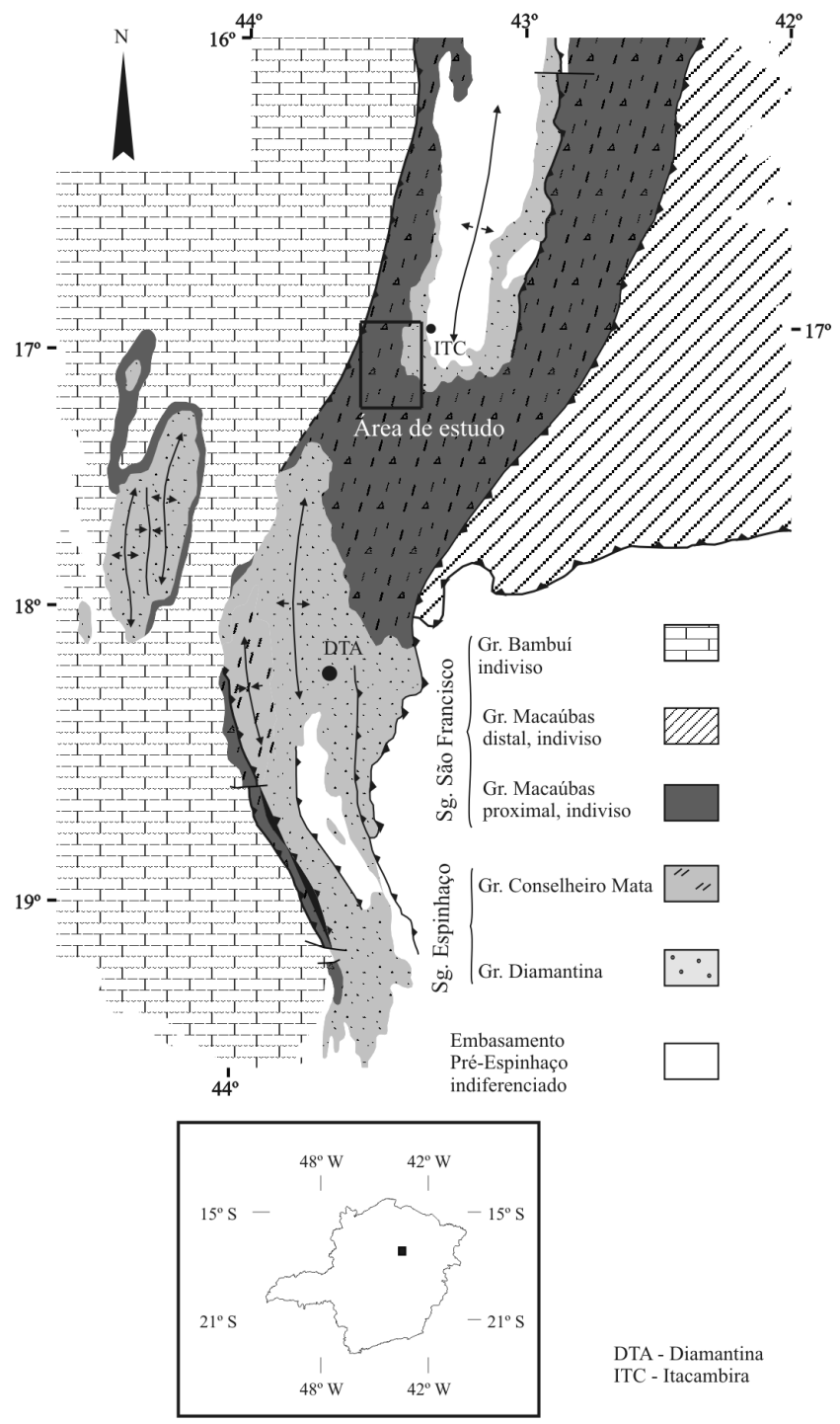

Figura 1 - Localização geográfica e posicionamento geotectônico da bacia do Rio Macaúbas (MG).

nico regional, inicialmente acompanhado de magmatismo de caráter básico por volta de 1,0 Ga (Uhlein et al. 1995, Pedrosa-Soares et al. 2001, Gradim et al. 2005). Comporta uma seqüência proximal, formada por depósitos pré-glaciais, glaciais e transicionais e outra distal, que encerra turbiditos de margem passiva e restos ofiolíticos (Pedrosa-Soares et al. 1998, 2001). O rifteamento teria sido entre $c a .1000$ e $880 \mathrm{Ma}$, e os registros de oceanização da bacia estariam em torno de $660 \mathrm{Ma}$ (Queiroga et al. 2007). É a principal unidade litoestratigráfica do Orógeno Araçuaí, possuindo espessura de alguns quilômetros, constituído por diamictitos com gradação vertical e lateral para quartzitos e metapelitos. Apresenta polaridade sedimentar e amplo desenvolvimento faciológico no sentido NNW-SSE, com registro de todos os estágios de desenvolvimento bacinal de um rifte continental para uma margem passiva (Noce et al. 1993).

O Grupo Bambuí ocorre como cobertura sedimentar sobre o cráton ou como metassedimentos no 
Orógeno Araçuaí. Constitui-se de (meta) sedimentos carbonáticos e pelíticos, interpretados como depósitos de plataforma marinha estável e de bacia de antepaís (Martins-Neto \& Alkmim 2001).

TRABALHOS ANTERIORES Luciano Jacques de Moraes e colaboradores nas décadas de 1920 e 1930 (Moraes 1928, 1932, Moraes \& Guimarães 1930, Moraes et al. 1937) estabeleceram o conhecimento geológico pioneiro para o setor setentrional mineiro da Serra do Espinhaço. Posteriormente, Karfunkel \& Karfunkel (1977) mapearam a porção sul da Cordilheira do Espinhaço Setentrional na escala de 1:60.000, entre as localidades de Itacambira e Botumirim. Todas as investigações posteriores realizadas nesta área se apoiaram nas observações destes últimos autores.

A Formação Itacambiruçu foi descrita como sendo a unidade basal do Supergrupo Espinhaço, recobrindo as rochas do embasamento. Uhlein (1991) considerou esta formação como sendo o produto do retrabalhamento de parte do embasamento gnáissico-migmatítico em zonas de cisalhamento durante o evento Brasiliano, excluindo-a do domínio de metassedimentos do Supergrupo Espinhaço (Tab. 1). Desta forma, o arcabouço estratigráfico restringiu-se às três formações superiores, designadas como Resplandecente, Água Preta e Matão.

A Formação Resplandecente representa a unidade de maior espessura, atingindo aproximadamente $300 \mathrm{~m}$. É constituída por quartzitos maciços a friáveis, dependendo da quantidade de mica. Medidas de paleocorrentes indicam transporte de oeste para leste. A Formação Água Preta é constituída por quartzitos imaturos com intercalações de metabrecha e lentes de metaconglomerados monomíticos. A espessura varia de oeste para leste, diminuindo de $30 \mathrm{~m}$ até o completo desaparecimento neste sentido. A unidade de topo, Formação Matão, constitui-se de quartzitos e quartzitos micáceos idênticos aos da Formação Resplandecente. A espessura varia de 20 a $200 \mathrm{~m}$.

Noce (1997) considerou duas unidades distintas para o Supergrupo Espinhaço na Folha Itacambira. A Unidade Inferior englobou as três formações descritas por Karfunkel \& Karfunkel (1977), consistindo em um pacote monótono de quartzitos, puros a pouco micáceos, de granulação fina a média, mostrando alternância de bancos maciços e laminados com estratificações cruzadas freqüentes. Localmente ocorrem níveis de brecha e conglomerado. A Unidade Superior estende-se pela porção sudeste da Folha Itacambira, posicionada tectonicamente sobre rochas do Grupo Macaúbas. É constituída por uma intercalação de rochas quartzíticas, quartzo-filíticas e filíticas, encerrando corpos concordantes de xisto verde.

O Grupo Macaúbas foi originalmente definido com o "status" de formação por Moraes (1928), Moraes \& Guimarães (1930) e Moraes (1932) para designar a seqüência de "phyllonitos conglomeráticos, com algumas camadas associadas de quartzito" presentes na bacia do rio homônimo e na Serra do Catuní (Formação "Macahúbas"). Para a região de Itacambira-Botumirim, Karfunkel \& Karfunkel (1977) reconheceram as formações Califorme, Terra Branca e Carbonita. A Formação Califorme compõe-se de quartzitos com espessura de até $200 \mathrm{~m}$, com intercalações localizadas de metaconglomerado. A Formação Terra Branca é caracterizada como metatilitos, quartzitos e metasiltitos com seixos e fragmentos de rochas de dimensões e formas variáveis (30 a $350 \mathrm{~m}$ de espessura), ao passo que a Formação Carbonita constitui-se de quartzitos finos e micáceos, metasiltitos e filitos (até $300 \mathrm{~m}$ de espessura), aos quais se associam corpos de xistos verdes.

Noce et al. (1993) propuseram uma compartimentação para o Grupo Macaúbas segundo os três setores que marcariam as principais divisões estratigráficas deste grupo. Grande parte do Setor Meridional corresponde à área mapeada por Karfunkel \& Karfunkel (1977) e foram correlacionados da seguinte forma (Tab. 1).

A Unidade Superior de Noce (1997) constitui parte da Formação Carbonita - Grupo Macaúbas - de Karfunkel \& Karfunkel (1977). Entretanto, foi colocada como pertencente ao Supergrupo Espinhaço levando-se

Tabela 1 - Estratigrafia comparativa para o Supergrupo Espinhaço e Grupo Macaúbas segundo os trabalhos de Karfunkel \& Karfunkel (1977) e Noce (1997).

\begin{tabular}{|c|c|c|c|}
\hline \multicolumn{3}{|c|}{ Karfunkel \& Karfunkel (1977) } & Noce (1997) \\
\hline \multicolumn{3}{|c|}{ Grupo Macaúbas } & Grupo Macaúbas \\
\hline \multirow{4}{*}{ Formação Terra Branca } & \multirow{3}{*}{ Fácies Carbonita } & Superior & \multirow[b]{2}{*}{ Formação Chapada Acauã } \\
\hline & & Médio & \\
\hline & & Inferior & \multirow[b]{2}{*}{ Formação Serra do Catuni } \\
\hline & Fácies Caçaratiba & & \\
\hline \multicolumn{3}{|c|}{ Formação Califorme } & Formação Duas Barras \\
\hline \multicolumn{3}{|c|}{ Supergrupo Espinhaço } & Supergrupo Espinhaço \\
\hline \multicolumn{3}{|c|}{ Formação Matão } & \multirow{3}{*}{$\begin{array}{l}\text { Unidade Superior } \\
\text { Unidade Inferior }\end{array}$} \\
\hline \multicolumn{3}{|c|}{ Formação Água Preta } & \\
\hline \multicolumn{3}{|c|}{ Formação Resplandecente } & \\
\hline \multicolumn{3}{|c|}{ Formação Itacambiruçu } & Embasamento milonitizado (Uhlein 1991) \\
\hline
\end{tabular}


em consideração que os xistos verdes e unidades às quais se associam seriam representantes do magmatismo bimodal da abertura do rifte Espinhaço na região situada imediatamente ao sul da Folha Itacambira - Folha Carbonita (Grossi-Sad et al. 1997). Contudo, Gradim et al. (2005) demonstraram que os xistos verdes na região do Alto Rio Araçuaí e que se prolongam em direção norte, pertencem ao magmatismo básico da abertura da bacia Macaúbas, com idade máxima em torno de 1,16 Ga. Desta forma, a compartimentação estratigráfica levantada por Karfunkel \& Karfunkel (1977) para o Supergrupo Espinhaço (à exceção da Formação Itacambiruçu) e para o Grupo Macaúbas na região de Itacambira-Botumirim foi confirmada pela edição do último "Mapa Geológico do Estado de Minas Gerais" (Pinto et al. 2003).

\section{GEOLOGIA DA BACIA DO RIO MACAÚBAS:} CONSIDERAÇÕES GERAIS O mapeamento geológico desta região (Fig. 2 e 3) baseou-se no levantamento de seções E-W, transversais ao Rio Macaúbas e ao longo de seus principias tributários (Martins 2006). As litofácies características para cada seção constituíram a base para correlações estratigráficas locais, onde foram agrupadas segundo o conceito de unidade litoestratigáfica definido pelo Código Brasileiro de Nomenclatura Estratigráfica (Petri et al. 1986) e pelo Guia Estratigráfico Internacional (Salvador 1994).

Nas descrições das unidades de natureza sedimentar suprimiram-se os termos metamórficos, uma vez que o baixo grau de recristalização dos protolitos possibilita identificar as texturas e estruturas originais das rochas.

Foi dada especial atenção no mapeamento de discordâncias erosivas ou superfícies de descontinuidades regionais, uma vez que superfícies desta natureza podem acumular tempo bem maior do que os próprios intervalos deposicionais presentes acima ou abaixo dela. Esta metodologia tem sido aplicada com sucesso nos estudos regionais enfocando os supergrupos Espinhaço e São Francisco (e.g. Danderfer \& Dardenne 2002, Martins-Neto 2007).

Adicionalmente aos levantamentos de campo, procedeu-se a amostragem de um afloramento de arenito da Formação Matão para estudos isotópicos (coordenadas: $8115122^{\mathrm{N}} 671844^{\mathrm{E}}$ ). Os concentrados de zircão foram obtidos no LOPAG-DEGEO/UFOP, por métodos convencionais (amostra OPU-2655). As análises isotópicas U-Pb foram realizadas em cristais de zircão pelo método SHRIMP (Sensitive High Resolution Ion Microprobe) no Beijing SHRIMP Laboratory, China. Procedimentos analíticos estão descritos em Compston et al. (1992). As idades foram calculadas através do software ISOPLOT (Ludwig 2001).

A integração entre os levantamentos estratigráficos e geocronológicos permitiu tecer um novo esboço sobre a evolução geológica do Supergrupo Espinhaço e do Grupo Macaúbas nesta região.

A Formação Resplandecente é a única unidade litoestratigráfica reconhecidas neste trabalho para o Supergrupo Espinhaço (Figs. 3 e 4), constituindo parte

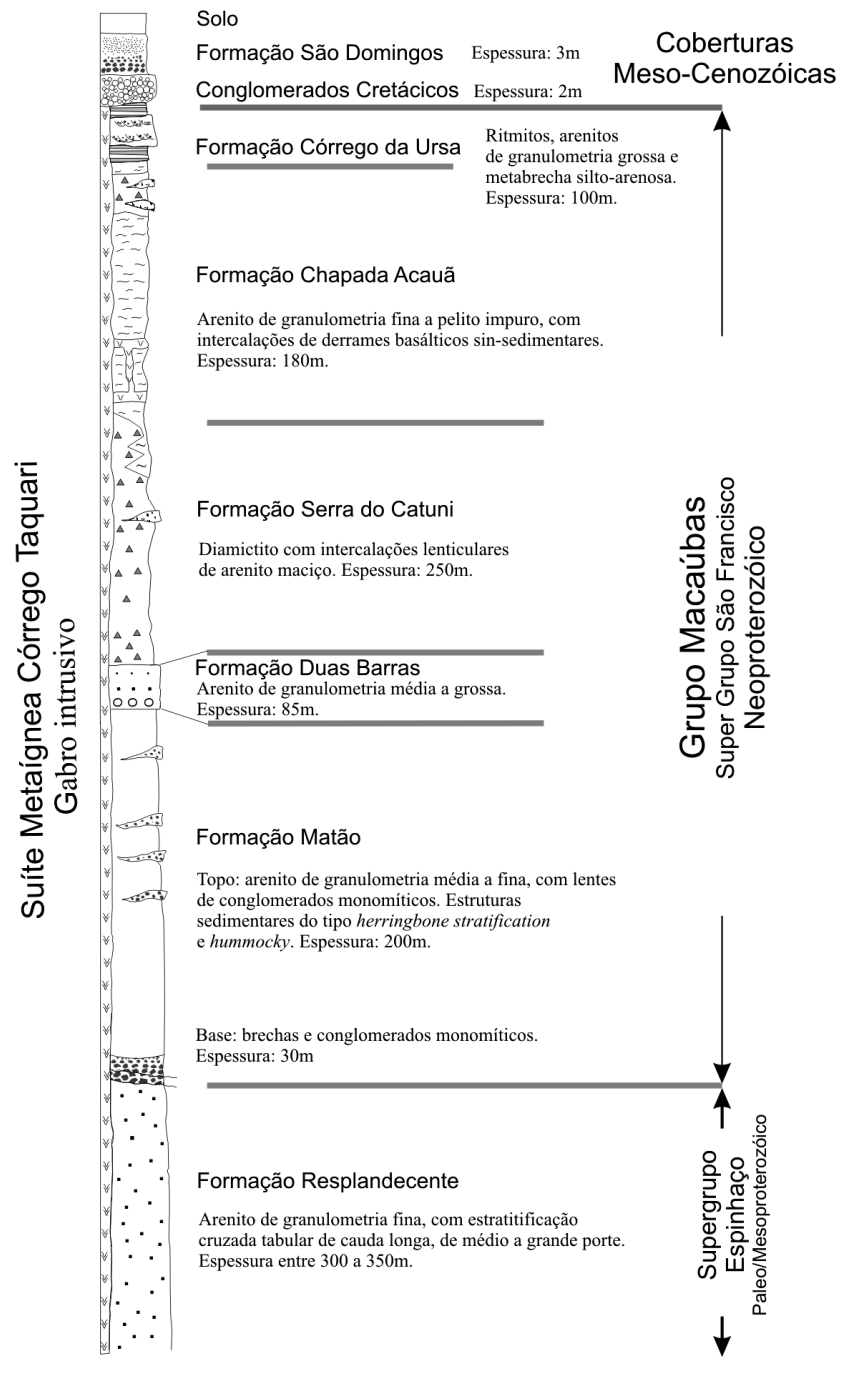

Figura 2 - Estratigrafia da região abrangida pela bacia hidrográfica do Rio Macaúbas (MG).

dos depósitos eólicos do estágio transicional definido por Martins-Neto (2007).

O Grupo Macaúbas é separado do Supergrupo Espinhaço por uma superfície de discordância erosiva não-contínua, parcialmente associada a falhamentos normais. Neste panorama, a Formação Matão representa o primeiro registro da fase de abertura continental do Rifte Araçuaí, englobando em sua porção basal as fácies rudíticas da Formação Água Preta de Karfunkel \& Karfunkel (1977). A idade máxima de sedimentação da Formação Matão é de 1,16 Ga (U-Pb SHRIMP em zircões detríticos), definida pela idade do zircão mais jovem datado.

As unidades sobrejacentes possuem equivalência com a pilha estratigráfica proposta por Noce et al. (1993) para o setor Meridional do Grupo Macaúbas em Minas Gerais (formações Duas Barras, Serra do Catuni e Chapada Acauã), acrescida da recém designada Formação Córrego da Ursa, topo do Grupo Macaúbas na bacia do rio homônimo. Dois períodos magmáticos são registrados nesta região (Martins 2006). O primeiro relaciona-se aos derrames basálticos da fase de abertura da bacia Araçuaí, ocorrendo como corpos de xis- 

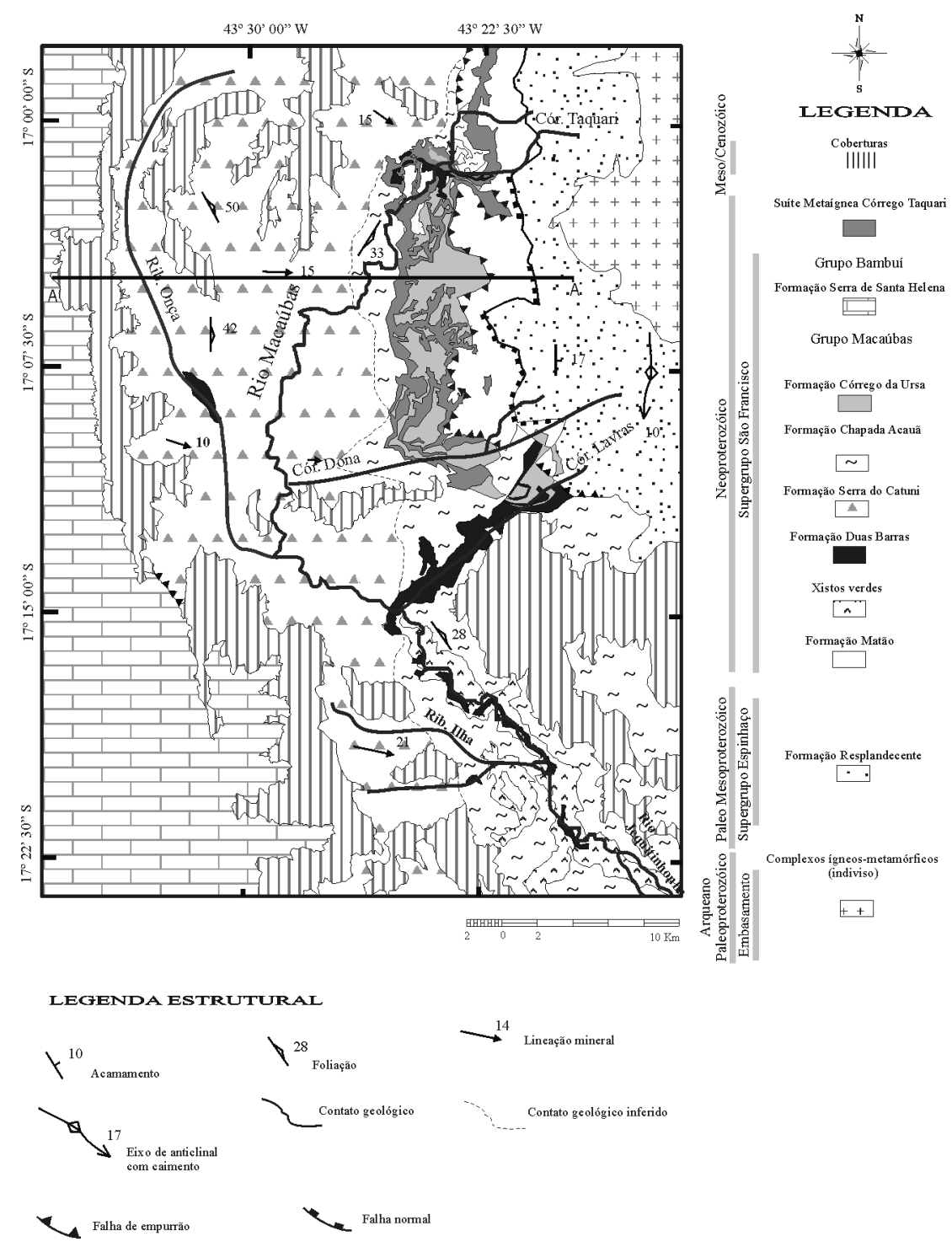

Figura 3 - Mapa geológico da região abrangida pela bacia hidrográfica do Rio Macaúbas (MG).

tos verdes, sem nomenclatura formal e equivalente ao Membro Rio Preto de Gradim et al. (2005); o segundo evento magmático é marcado por corpos de (meta) gabro que cortam toda a seqüência vulcano-sedimentar proterozóica. Provavelmente relacionam-se à tectônica compressiva do ciclo Brasiliano, no final do Neoproterozóico, e receberam a denominação de Suíte Metaígnea Córrego Taquari.

Dada a área de interesse do presente trabalho serão consideradas apenas as unidades pré-glaciais do Grupo Macaúbas nesta região (i.e. formações Matão e Duas Barras).

\section{SUPERGRUPO ESPINHAÇO - FORMAÇÃO} RESPLANDECENTE A Formação Resplandecente é a única unidade litoestratigráfica do Supergrupo Espinhaço ao longo do Anticlinal de Itacambira, assentando-se diretamente sobre as rochas do embasamento (Fig. 3). Possui grande distribuição areal, estendendo- se amplamente nas direções E-W e N-S. A espessura estimada para este pacote possui valor máximo em torno de 300 a $350 \mathrm{~m}$. É formada por um pacote homogêneo de arenitos finos a médios, composicionalmente e texturalmente maturos. Localmente observam-se pequenas variações granulométricas, tais como lentes milimétricas de quartzo de granulação grossa. Duas estruturas primárias ocorrem associadas aos arenitos da Formação Resplandecente: planos de estratificação cruzada de grande porte e marcas onduladas. Os planos de estratificação cruzada quase sempre são tabulares a tangenciais de cauda longa, de médio a grande porte (Fig. 4A). Alguns sets cruzados chegam a atingir mais de $6 \mathrm{~m}$ de espessura, estendendo-se por distâncias superiores a $10 \mathrm{~m}$. As medidas de paleocorrentes nas áreas compreendidas entre os córregos da Dona e Lavras apresentam-se genericamente unipolares, com aporte sedimentar de NW para SE (Fig. 4B). As marcas de onda ocorrem em poucos locais sendo geralmente 
simétricas, pouco sinuosas, de baixa amplitude (menos de $1 \mathrm{~cm}$ ) e comprimento de onda de $10 \mathrm{~cm}$.

GRUPO MACAÚBAS: ESTRATIGRAFIA DA SEQÜÊNCIA PRÉ-GLACIAL A base do Grupo Macaúbas, redefinida neste trabalho, é formada por uma associação de brechas e conglomerados monomíticos na base, gradando verticalmente para um espesso pacote de arenito em direção ao topo. Corresponde à Formação Matão de Karfunkel \& Karfunkel (1977), englobando a Formação Água Preta em sua porção basal. Recobre descontinuamente a Formação Resplandecente por discordância erosiva (Fig. 5A), localmente limitada por falhas normais (Fig. 5B).

Os corpos de brechas ocorrem desde a região do Córrego das Lavras, prolongando-se segundo o meridiano até a nascente do Rio Macaúbas. Os clastos são constituídos por arenitos de granulação fina, homogêneos, variando de seixo a bloco (Fig. 5C), com ocorrências esparsas de matacão. Predominam brechas suportadas pelos clastos. O pacote de brechas, por vezes, apresenta uma superfície de discordância erosiva interna, separando-o em níveis inferior e superior (Fig. 5D). O nível superior mostra granodecrescência ascendente, transicionando para um arenito de granulação grossa. Os corpos de conglomerados monomíticos distribuemse ao longo da área abrangida entre os córregos da Dona e Lavras, sobrepondo os arenitos da Formação Resplandecente por discordância erosiva. A exemplo de algumas exposições de brecha, observa-se uma granodecrescência ascendente deste pacote, cujo arcabouço interno transiciona de um tipo clasto-suportado para matriz suportado.

O topo da Formação Matão apresenta maior espessura na porção setentrional da área, atingindo valores da ordem de $200 \mathrm{~m}$. É formada essencialmente por arenitos, localmente com intercalações de conglomerados monomíticos em direção ao topo. A granulometria varia de média a fina em todo o pacote, localmente grossa na base, possuindo elevado grau de maturidade composicional e textural. O perfil levantado ao longo do Córrego Taquari evidencia o posicionamento estratigráfico das principais estruturas sedimentares presentes nesta formação. Na base ocorrem estratificações cruzadas de baixo ângulo, cujas espessuras dos sets cruzados situam-se entre 10 a $50 \mathrm{~cm}$, estratificações cruzadas tabulares de pequeno porte, truncadas no topo e na base por estratos plano-paralelos (Fig. 5E) e por estratificações cruzadas tangenciais de pequeno porte do tipo "espinha de peixe" (herringbone stratification). Em direção ao topo, observam-se estratos plano-paralelos sobrepostos por estratificações cruzadas por ondas (hummocky, Fig. $5 \mathrm{~F}$ ) e marcas onduladas sinuosas e assimétricas, com amplitude da ordem de $1 \mathrm{~cm}$ e comprimento de onda variando de 2 a $4 \mathrm{~cm}$. O padrão de paleocorrentes é unipolar, com aporte sedimentar principal para WNW (Fig. 6). Os corpos de conglomerado são constituídos por clastos de arenito e subordinadamente de quartzo, suportados pelos clastos. Apresentam ainda bom grau de arredondamento.

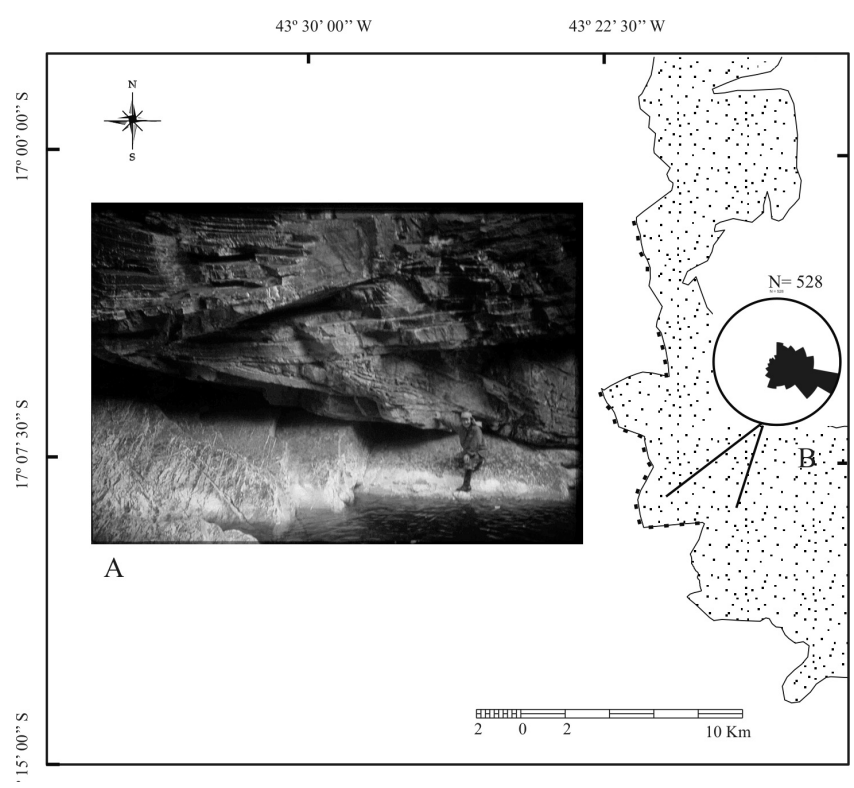

Figura 4 - A) Estratificação cruzada tangencial de cauda longa e de grande porte da Formação Resplandecente, Supergrupo Espinhaço (Córrego da Dona, vista de NE para SW). B) Padrão de paleocorrentes da Formação Resplandecente.

Quinze grãos de zircão com morfologias diversas foram selecionados para análise por SHRIMP (Fig. 7). Alguns cristais mostram-se incipientemente arredondados, evidenciando seu caráter detrítico. As idades obtidas variaram entre $c a$. 1,16 Ga e 2,80 Ga (Tab. 2). A grande maioria das datações individuais é muito pouco discordante (Tab. 2, Fig. 8). Em função das correções de $\mathrm{Pb}$ comum nas razões isotópicas obtidas durante as análises dos minerais datados, as idades ${ }^{238} \mathrm{U}^{206} \mathrm{~Pb}$ melhor representariam a época de cristalização de grãos mais jovens que $1,5 \mathrm{Ga}$, enquanto para os cristais mais antigos as idades ${ }^{207} \mathrm{~Pb}-{ }^{206} \mathrm{~Pb}$ são mais apropriadas (marcadas em negrito na Tab. 2). Dos quinze spots analisados (um em cada cristal de zircão), nove apresentam discordância absoluta menor ou igual a $5 \%$, sendo que quatro apresentam discordância relativamente pequena (módulo menor ou igual a 8). Apenas as idades obtidas nos spots $12.1 \mathrm{e}$ 13.1 apresenta discordância acima desta faixa e não serão considerados nas interpretações. As idades mais jovens do conjunto, obtidas nos spots 1.1,3.1 e 5.1, apresentam discordâncias negativa de $8 \%$ e positiva de $1 \%$, respectivamente. Os cristais de zircão analisados são todos de origem magmática, conforme indicado por suas razões ${ }^{232} \mathrm{Th} /{ }^{238} \mathrm{U}$ relativamente altas (Tab. 2).

Imagens de catodoluminescência corroboram esta evidência geoquímica, mostrando zoneamento oscilatório tipicamente magmático, presente em núcleos e/ou sobrecrescimentos magmáticos em muitos cristais (Fig. 7). Nenhum dos cristais analisados apresenta sobrecrescimento metamórfico. Os grãos de zircão analisados foram separados por idade ou intervalos de idade, a fim de facilitar a identificação de possíveis relações entre idade e morfologia (Fig. 8). As idades obtidas nos spots foram agrupadas também com vistas a correla- 

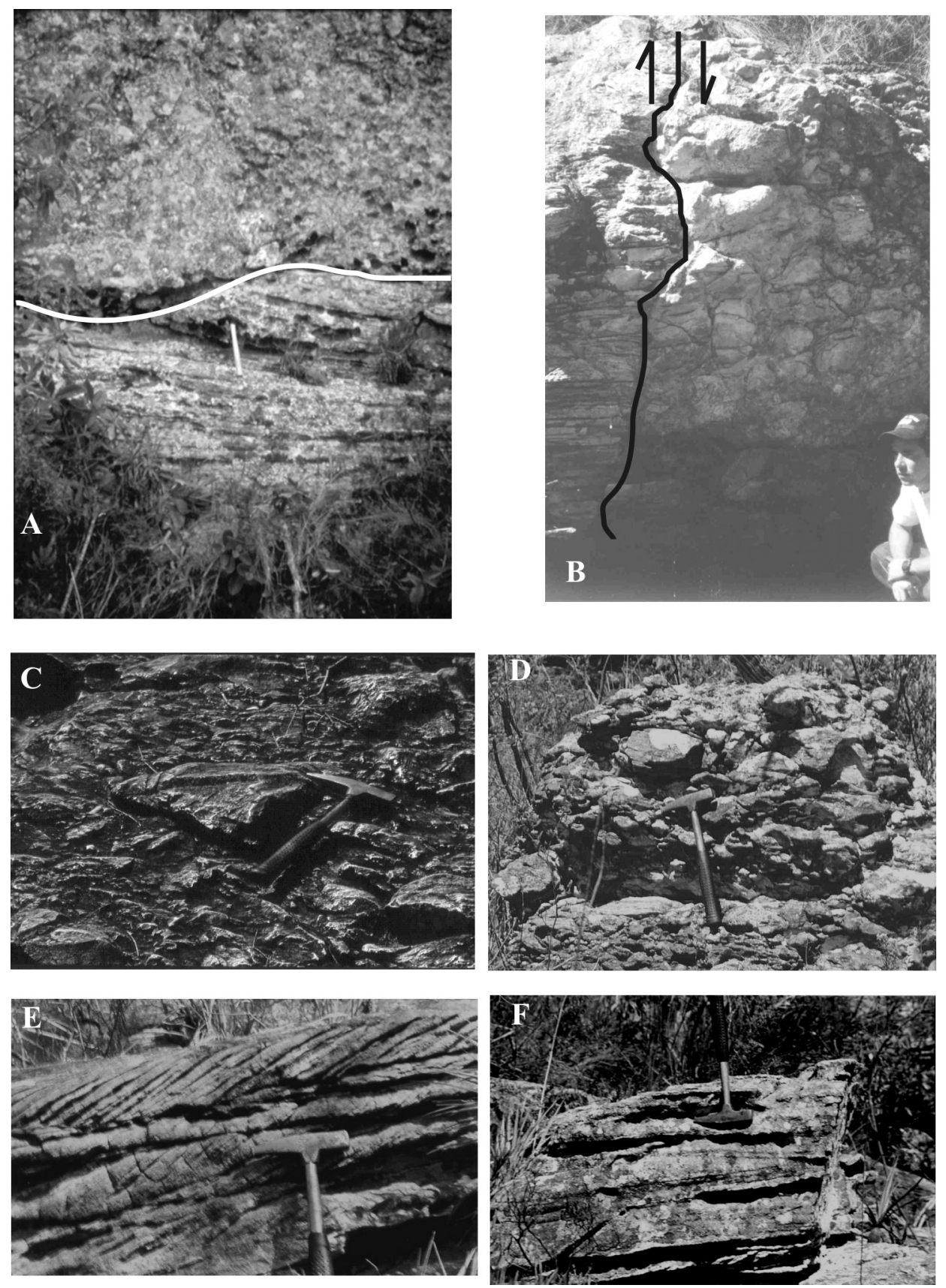

Figura 5 - Principais estruturas sedimentares da Formação Matão, Grupo Macaúbas. A) contato erosivo entre arenito da Formação Resplandecente - Supergrupo Espinhaço (na base) e conglomerado monomítico da Formação Matão, no topo (Córrego da Dona, vista de S para N). B) falha normal com indicação de movimentação dos blocos separando arenito da Formação Resplandecente (a esquerda da falha) do pacote de brecha monomítica da Formação Matão (Córrego da Dona, vista de N para S). C) detalhe da brecha monomítica (Córrego da Dona, vista de $S$ para N). D) contato erosivo separando dois niveis de brecha-conglomerática intraformacional (vista de SW para NE). E) "descontinuidades" plano-paralelas que limitam os foresets da estratificação cruzada tabular de pequeno porte (vista de $S$ para N). F) estratificação cruzada por onda "hummocky" (vista de SW para NE).

ções com eventos geológicos conhecidos. Enfatiza-se que, como os cristais de zircão são originalmente magmáticos e livres de bordas metamórficas, esses intervalos de idades apontam somente episódios magmáticos (i.e., nenhum deles sugere evento metamórfico).

As idades U-Pb SHRIMP dos zircões detríticos separados desta formação variaram de 2,8 a 1,16 Ga e indicam fontes essencialmente paleoproterozóicas $(1,9$ 


\section{a 2,2 Ga) e mesoproterozóicas.}

O conjunto de idades mais jovem $(c a .1,2 \mathrm{Ga})$ é o mais importante no contexto desta investigação, pois define a idade máxima de sedimentação da Formação Matão. Neste grupo, o cristal de zircão do spot 5.1 apresenta zoneamento oscilatório tipicamente magmático e idade de $c a$. 1,16 Ga.

A Formação Duas Barras apresenta relativa homogeneidade com relação à textura, composição e estruturas sedimentares. Está exposta descontinuamente em núcleos de anticlinais ao longo do Rio Macaúbas, Ribeirão do Onça e dos córregos Taquari e Saco de Mel (Fig. 3). Compõe-se de arenitos de granulometria grossa, com níveis conglomeráticos, texturalmente maturos. $\mathrm{O}$ acamamento é definido por estratos de até $50 \mathrm{~cm}$ de espessura (Fig. 9A), limitado por estratificações cruzadas tangenciais de baixo ângulo e de pequeno porte (em torno de $50 \mathrm{~cm}$ de set cruzado). Ocorrem ainda marcas onduladas assimétricas, na forma de lunatas irregulares, cujos comprimentos de onda são da ordem 8 a $10 \mathrm{~cm}$ de extensão e amplitude da ordem de aproximadamente 1 cm (Fig. 9B). Na porção mediana do Córrego Taquari, a Formação Duas Barras apresenta um pacote de arenito de granulometria predominantemente média, de aspecto maciço, com intercalações lenticulares de material ferruginoso (Fig. 9C), variando de 10 a $60 \mathrm{~cm}$ de espessura

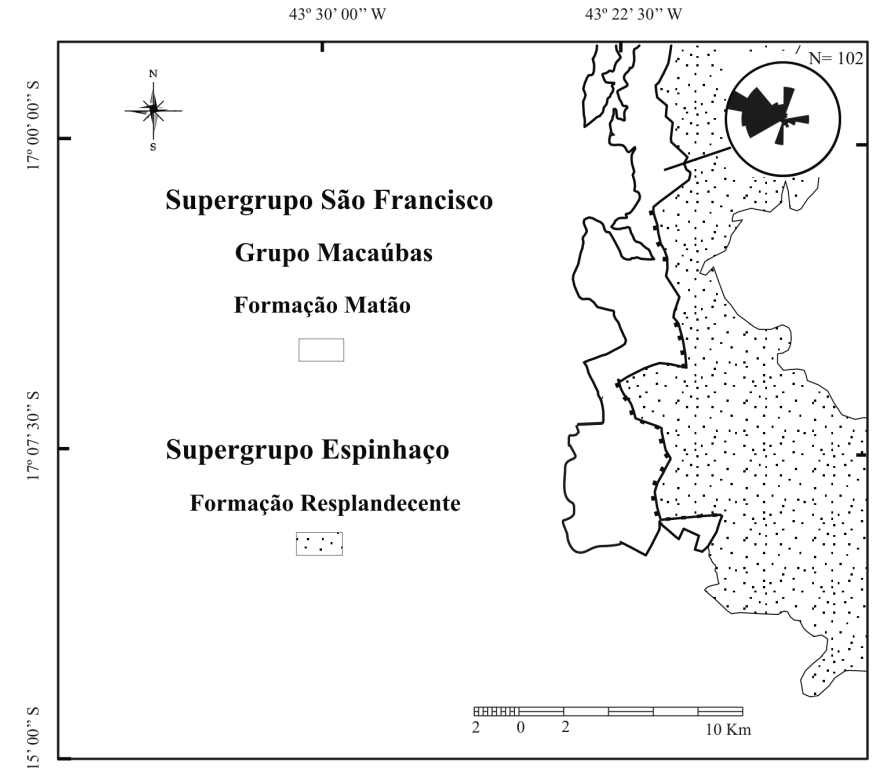

Figura 6 - Roseta de paleocorrentes da Formação Matão na bacia do rio homônimo.

e estendendo-se continuamente por até $1 \mathrm{~km}$.O vetor de paleocorrente é de NW para SE ao longo do Ribeirão do Onça, Córrego das Lavras e Rio Macaúbas (Fig. 10). Na
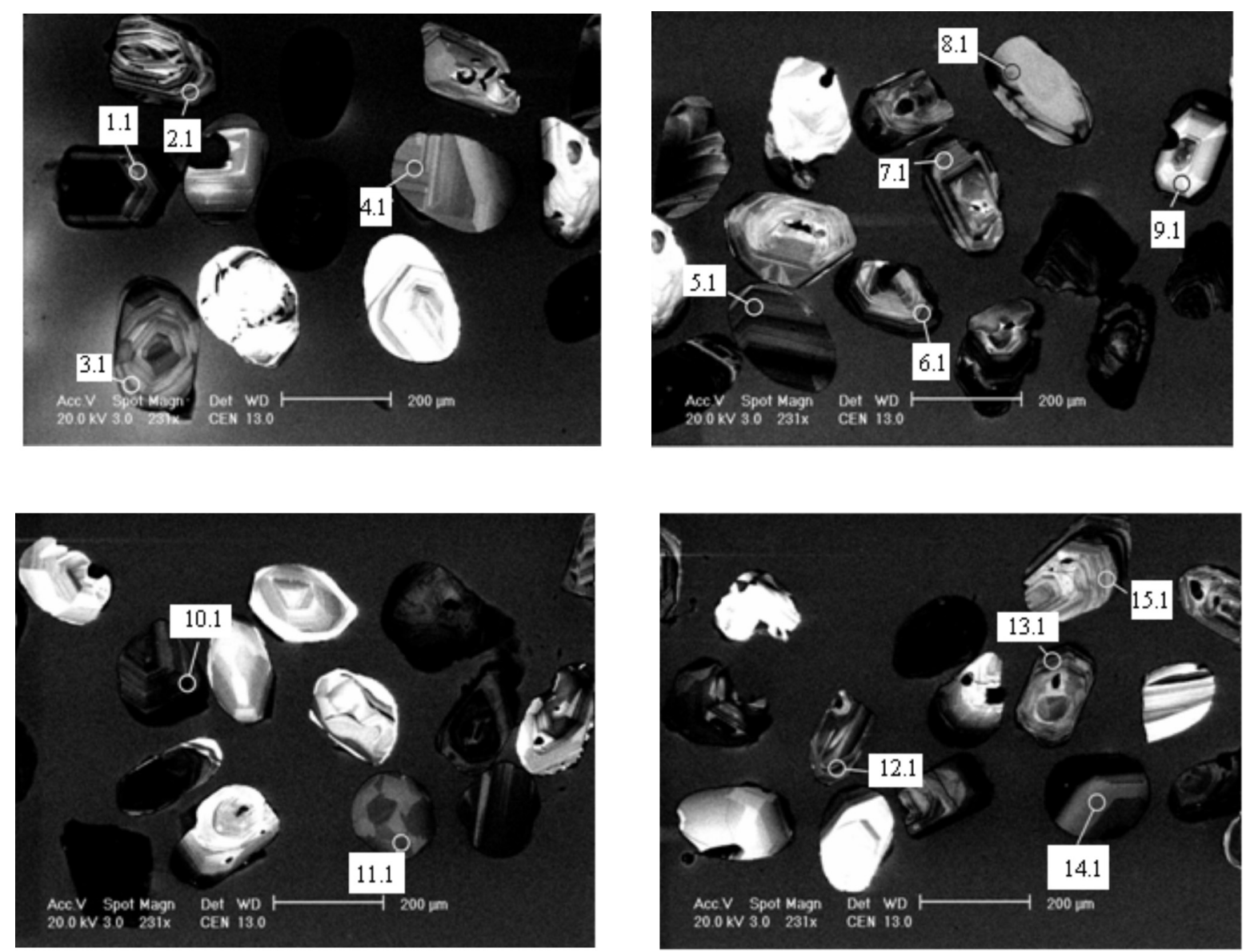

Figura 7 - Imagens de catodoluminescência dos grãos de zircão e respectivos spots analisados (indicados com círculo e numerados). 
Tabela 2 - Dados analíticos obtidos nos cristais de zircão detríticos da Formação Matão, Grupo Macaúbas.

\begin{tabular}{|c|c|c|c|c|c|c|c|c|c|c|c|c|c|c|c|c|}
\hline \multirow{2}{*}{$\begin{array}{c}\text { Spot } \\
1.1\end{array}$} & \multirow{2}{*}{\begin{tabular}{|c|c}
$\begin{array}{c}\mathbf{\%} \\
{ }^{206} \mathbf{P b}_{\mathbf{c}}\end{array}$ \\
0,31
\end{tabular}} & \multirow{2}{*}{$\begin{array}{c}\text { ppm } \\
\mathbf{U} \\
145\end{array}$} & \multirow{2}{*}{$\begin{array}{c}\text { ppm } \\
\text { Th } \\
74\end{array}$} & \multirow{2}{*}{$\begin{array}{r}{ }^{{ }^{232} \mathbf{T h}} \\
{ }^{238} \mathbf{U}\end{array}$} & \multirow{2}{*}{$\begin{array}{c}\underset{{ }^{206} \mathbf{P b}^{*}}{\mathbf{p p m}} \\
26.9\end{array}$} & \multicolumn{2}{|c|}{$\begin{array}{c}\text { Idade } \\
{ }^{206} \mathrm{~Pb} /{ }^{238} \mathrm{U} \\
\mathrm{Ga}\end{array}$} & \multicolumn{2}{|c|}{$\begin{array}{c}\text { Idade } \\
{ }^{207} \mathrm{~Pb} /{ }^{206} \mathrm{~Pb} \\
\mathrm{Ga}\end{array}$} & \multirow{2}{*}{$\begin{array}{c}\begin{array}{c}\% \\
\text { Disc. }\end{array} \\
-8\end{array}$} & \multirow{2}{*}{$\frac{{ }^{207} \mathbf{P b}^{*} /{ }^{206} \mathbf{P b}^{*}}{0.0786}$} & \multirow{2}{*}{$\begin{array}{r}\mathbf{\pm \%} \\
2.8\end{array}$} & \multirow{2}{*}{$\frac{{ }^{207} \mathbf{P} \mathbf{b}^{* / 235} \mathbf{U}}{2.323}$} & \multirow{2}{*}{$\begin{array}{r}\mathbf{\pm \%} \\
3.5\end{array}$} & \multirow{2}{*}{$\frac{{ }^{206} \mathbf{P b}^{* / 238} \mathbf{U}}{0.2143}$} & \multirow{2}{*}{$\begin{array}{r}\mathbf{\pm \%} \\
2.1\end{array}$} \\
\hline & & & & & & 1,252 & \pm 24 & 1,163 & \pm 55 & & & & & & & \\
\hline 2.1 & 0,48 & 115 & 137 & 1,23 & 39.2 & 2,143 & \pm 39 & 2,187 & \pm 23 & 2 & 0.1368 & 1.3 & & 2.5 & 0.3943 & 2.2 \\
\hline 3.1 & 0,34 & 82 & 33 & 0,41 & 15.1 & 1,250 & $\pm \mathbf{2 5}$ & 1,257 & \pm 51 & 1 & 0.0825 & 2.6 & 2.434 & 3.4 & 0.2140 & 2.2 \\
\hline 4.1 & 0,26 & 76 & 28 & 0,38 & 19.7 & 1,702 & \pm 33 & 1,645 & $\pm \mathbf{3 3}$ & -4 & 0.1011 & 1.8 & 4.21 & 2.9 & 0.3022 & 2.2 \\
\hline 5.1 & 0,22 & 177 & 80 & 0,47 & 30.1 & 1,161 & $\pm \mathbf{2 3}$ & 1,177 & \pm 30 & 1 & 0.0792 & 1.5 & 2.154 & 2.6 & 0.1973 & 2.2 \\
\hline 6.1 & 0,17 & 78 & 50 & 0,66 & 27.5 & 2,212 & \pm 44 & 2,082 & $\pm \mathbf{2 3}$ & -6 & 0.1288 & 1.3 & 7.2 & 2.7 & 0.4093 & 2.3 \\
\hline 7.1 & 0,47 & 128 & 108 & 0,87 & 30.1 & 1,555 & \pm 30 & 1,501 & $\pm \mathbf{3 4}$ & -4 & 0.0936 & 1.8 & 3.522 & 2.8 & 0.2728 & 2.1 \\
\hline 8.1 & 0,21 & 69 & 101 & 1,52 & 23.8 & 2,173 & \pm 41 & 2,091 & \pm 26 & -4 & 0.1295 & 1.5 & 7.16 & 2.7 & 0.4009 & 2.2 \\
\hline 9.1 & 0,60 & 51 & 75 & 1,50 & 14.0 & 1,771 & \pm 39 & 1,917 & $\pm \mathbf{4 2}$ & 8 & 0.1174 & 2.4 & 5.12 & 3.4 & 0.3161 & 2.5 \\
\hline 10.1 & 0,30 & 146 & 97 & 0,69 & 46.1 & 2,015 & \pm 38 & 1,979 & \pm 21 & -2 & 0.1216 & 1.2 & 6.15 & 2.5 & 0.3669 & 2.2 \\
\hline 11.1 & 0,11 & 87 & 38 & 0,45 & 32.3 & 2,311 & \pm 42 & 2,152 & $\pm \mathbf{2 0}$ & -7 & 0.1341 & 1.1 & 7.97 & 2.5 & 0.4313 & 2.2 \\
\hline 12.1 & 0,20 & 158 & 145 & 0,95 & 46.6 & 1,901 & \pm 35 & 2,135 & $\pm \mathbf{2 0}$ & 11 & 0.1328 & 1.1 & 6.28 & 2.4 & 0.3430 & 2.1 \\
\hline 13.1 & 0,58 & 136 & 277 & 2,10 & 29.6 & 1,445 & \pm 28 & 1,943 & \pm 29 & 26 & 0.1191 & 1.6 & 4.13 & 2.7 & 0.2513 & 2.1 \\
\hline 14.1 & 0,14 & 68 & 112 & 1,70 & 32.1 & 2,824 & \pm 54 & 2,805 & $\pm \mathbf{1 7}$ & -1 & 0.1974 & 1.0 & 14.96 & 2.6 & 0.550 & 2.4 \\
\hline 15.1 & 0,35 & 72 & 106 & 1,52 & 21.9 & 1,952 & \pm 38 & 1,927 & $\pm \mathbf{2 9}$ & -1 & 0.1180 & 1.6 & 5.75 & 2.8 & 0.3536 & 2.2 \\
\hline
\end{tabular}

Erros são 1 sigma. $\mathrm{Pb}_{\mathrm{c}}$ e $\mathrm{Pb} *$ representam chumbo comum e radiogênico, respectivamente. Idades em negrito representam a idade de cristalização do mineral. \% Disc = percentual de discordância.

porção mediana do Córrego das Lavras, pôde-se estimar a espessura do pacote em torno de $85 \mathrm{~m}$.

DISCUSSÃO: EVOLUÇÃO SEDIMENTAR E ESTRATIGRAFIA REDEFINIDA PARA SUPERGRUPO ESPINHAÇO E DA SEQÜÊNCIA RIFTE DO ORÓGENO ARAÇUAÍ A integração entre os levantamentos estratigráficos e geocronológicos permitiu tecer um novo esboço sobre a evolução geológica do Supergrupo Espinhaço e, principalmente, do Grupo Macaúbas nesta região.

A deposição do Supergrupo Espinhaço é relacionada com a implantação de um sistema desértico diretamente sobre o embasamento Arqueano/ Paleoproterozóico. A Formação Resplandecente é interpretada como remanescente de dunas eólicas formadas por ventos unidirecionais (barcanas), correlacionáveis ao sistema deposicional desértico, provavelmente de clima árido. São típicas de grandes áreas de acumulação de areia e baixa umidade, cuja fonte dos sedimentos estaria relacionada aos terrenos do Continente São Francisco-Congo, a oeste. Segundo Martins-Neto (2007), este nível estratigráfico marcaria o estágio de transição entre as seqüências pré-rifte e rifte para o estágio flexural de evolução da bacia "Espinhaço" (ca.1750 a $1500 \mathrm{Ma}$ ).

O registro da fase de abertura do Rifte Araçuaí nesta região é marcado por um período de instabilidade tectônica, materializado pela superfície de contato erosiva entre o Supergrupo Espinhaço e o Grupo Macaúbas. Dado o lapso de tempo envolvido por esta superfície erosiva e o seu significado geotectônico, esta pode ser designada como uma discordância de primeira ordem de grandeza. Neste contexto, a Formação Matão é redefinida neste trabalho como base do Grupo Macaúbas.

A deposição iniciou-se com a fragmentação sinsedimentar de camadas já consolidadas - dunas eólicas

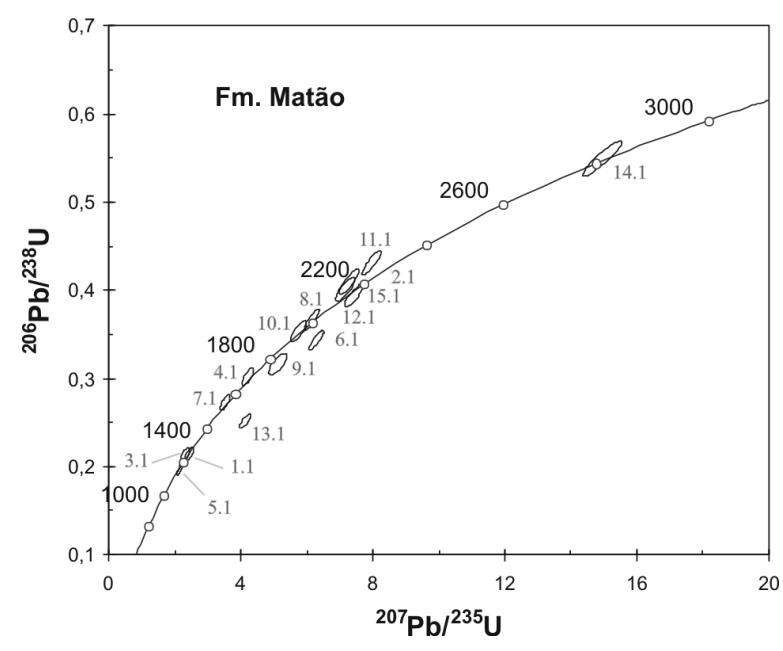

Figura 8 - Diagrama U-Pb concórdia dos zircões detríticos da Formação Matão. Números marcados representam os zircões datados e cujos dados analíticos são apresentados na tabela 2.

da Formação Resplandecente - com redeposição através de fluxo de massa. A granodecrescência ascendente provavelmente está relacionada à mudança nas condições do regime de fluxo: inicialmente fluxos turbulentos de alta viscosidade associada com a alta concentração de sedimentos, gradando para fluxos turbulentos com baixa concentração de sedimento.

Em direção ao topo, os sedimentos da Formação Matão apresentam estruturas sedimentares características de ambiente marinho raso, evidenciando um evento transgressivo. As estruturas do tipo "espinha-de-peixe" (herringbone stratification) representam a migração lateral de barras longitudinais (dunas subaquosas) sob a ação de correntes de maré em ambiente marinho raso. As descontinuidades plano-paralelas que limitam os 

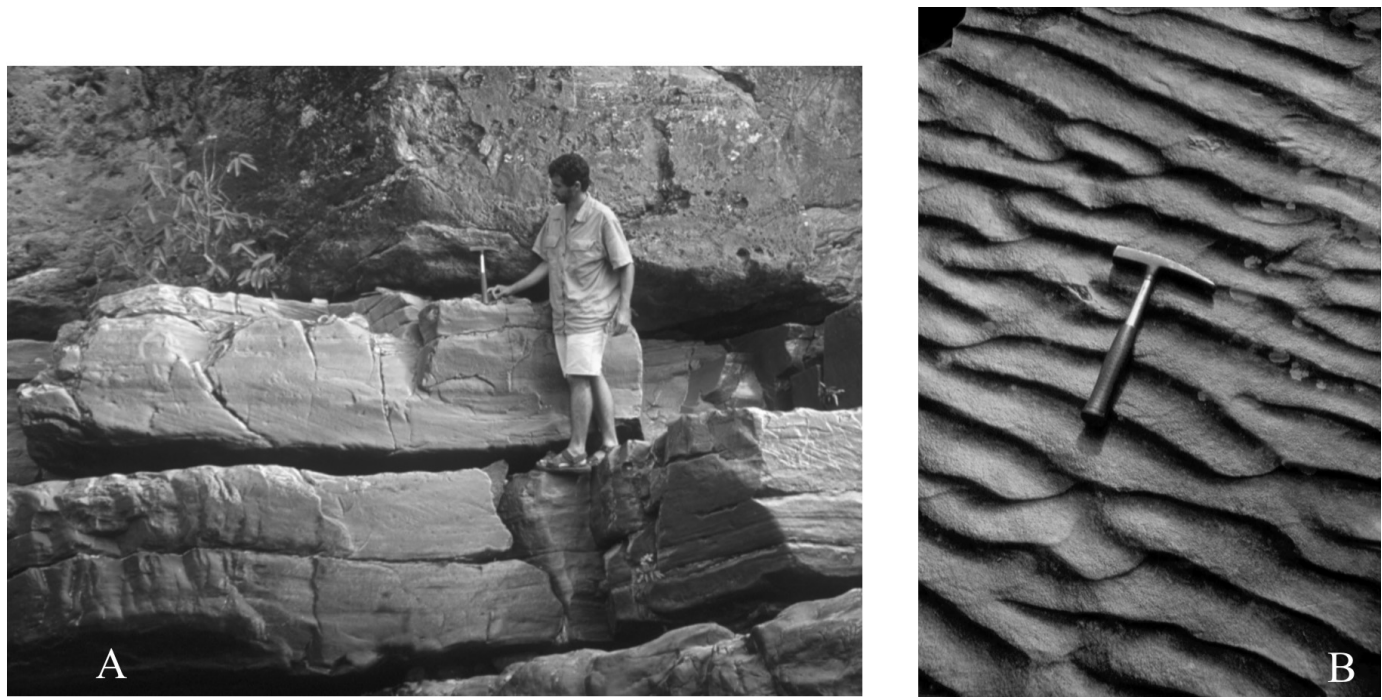

Figura 9 - Feições sedimentares presentes na Formação Duas Barras. A) contato brusco entre o arenito da Formação Duas Barras, sobreposto pelo diamictito da Formação Serra do Catuni (vista de SW para NE). B) marcas onduladas assimétricas, na forma de lunatas irregulares em arenito da Formação Duas Barras (vista de SE para NW).

foresets da estratificação cruzada tabular de pequeno porte representam "superfícies de reativação" oriundos da modificação de fluxos de ambiente de maré, seguido por fluxo dominante posterior. A estratificação por ondas (hummocky) constitui o registro da sedimentação em plataforma marinha rasa sob influência de tempestades ocasionais.

Os cristais de zircão analisados são considerados como xenocristais provenientes de rochas magmáticas de idades variadas. Essa interpretação é sugerida pelo freqüente zoneamento oscilatório, pelas altas razões ${ }^{232} \mathrm{Th} /{ }^{238} \mathrm{U}$, ausência de sobrecrescimento metamórfico e morfologias diversas.

$\mathrm{O}$ conjunto 1,9-2,1 Ga pode ser relacionado à Orogenia Transamazônica que produziu grande volume de rochas magmáticas bem representadas no embasamento do Orógeno Araçuaí. Os outros valores de idades não apresentam correlações tão diretas. A idade arqueana do spot 14.1 ( $c a .2,82 \mathrm{Ga})$ é correlacionável com a datação de $c a$. 2,84 Ga obtida por Machado et al. (1989) e com as idades de $c a$. 2,87 e 2,71 Ga (Silva et al. 2002, Noce et al. 2003).

O conjunto do intervalo 1,6-1,7 Ga pode ser relacionado ao magmatismo félsico da abertura do rifte Espinhaço e está dentro da gama de idades $(1,77-1,67 \mathrm{Ga})$ da Suíte Borrachudos (Machado et al. 1989, Silva et al. 2002, Noce et al. 2003).

O conjunto 1,4-1,5 Ga não encontra uma concentração equivalente bem estabelecida na literatura, mas valores similares foram obtidos para a cristalização magmática do protólito de anfibolito associado ao Complexo Pocrane (Silva et al. 2002), do embasamento do arco magmático do Orógeno Araçuaí, e em um sill associado aos arenitos da Formação Mangabeira da Chapada Diamantina, Bahia (Babinski et al., 1999).

O conjunto de idades mais jovem $(c a .1,16 \mathrm{Ga})$

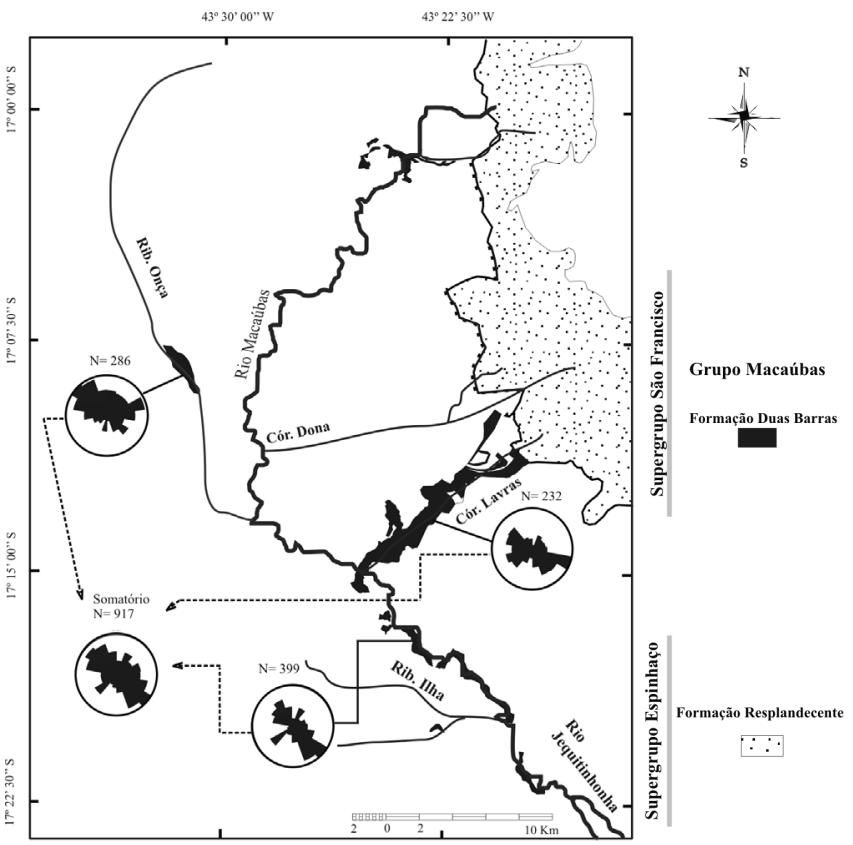

Figura 10 - Rosetas de paleocorrente da Formação Duas Barras, Grupo Macaúbas.

é o mais importante no contexto desta investigação, pois define a idade máxima da Formação Matão. Os vetores de paleocorrentes indicam aporte sedimentar a partir de fonte(s) localizada(s) a leste da atual bacia do Rio Macaúbas, provavelmente oriundas do Cráton do Congo.

A Formação Duas Barras é interpretada como remanescente de sedimentos marinhos costeiros a fluviais, onde os arenitos de granulação grossa estariam relacionados a fluxos oscilatórios de alta energia, com geração de ripples assimétricas em zona de arrebenta- 
ção, evidenciado pelo padrão de distribuição das paleocorrentes e maturidade textural. Os arenitos maciços e ferruginosos teriam sua formação relacionada a um ambiente marinho raso, com deposição química dos níveis de óxido de ferro. Considera-se que tanto o cráton São Francisco quanto o cráton Congo Oeste poderiam ter servido de fonte para estes sedimentos.

CONCLUSÕES Na bacia do Rio Macaúbas, o Supergrupo Espinhaço é formado unicamente pelos sedimentos eólicos da Formação Resplandecente, provavelmente cronocorrelatos aos da Formação Galho do Miguel, na Serra do Espinhaço Meridional, assentandose diretamente sobre o embasamento Arqueano/Paleoproterozóico. Representam a deposição relativamente tardia do Supergrupo Espinhaço neste segmento da bacia, possivelmente relacionados à migração dos sítios de sedimentação situados nas parcelas meridional e setentrional da bacia Espinhaço (Martins-Neto 1998, Danderfer \& Dardenne 2002).

O Grupo Macaúbas, alvo principal deste trabalho, foi redefinido nesta região. A Formação Matão é parcialmente limitadas por superfícies erosivas descontínuas, envolvendo um grande lapso de tempo entre o desenvolvimento das bacias "Espinhaço" e "Macaúbas" (descontinuidade de primeira ordem de grandeza).
Representa a fase de rifteamento continental de abertura da bacia Araçuaí. A deposição foi iniciada como resposta a um evento de distensão crustal, em que, num primeiro estágio, parte dos depósitos eólicos do Supergrupo Espinhaço foram retrabalhados dentro da própria bacia, seguida de uma transgressão marinha generalizada, em regime de subsidência mecânica. A idade máxima da Formação Matão é limitada pelo zircão detrítico mais jovem, datado em 1,16 Ga.

A Formação Duas Barras registra a evolução do processo de abertura do Rifte Araçuaí, com sedimentos marinhos costeiros de margem passiva a fluviais da fase rifte, texturalmente maturos e com padrão de paleocorrente bipolar. Infere-se que tanto o Cráton São Francisco como o Cráton do Congo possivelmente serviram como fonte para os sedimentos da Formação Duas Barras.

Agradecimentos Agradecemos ao CNPq e à FAPEMIG pelo financiamento de parte do projeto de pesquisa e bolsas de produtividade em pesquisa de J. Karfunkel, C.M. Noce, M. Babinski, A.C. Pedrosa-Soares, e A.N. Sial, à CAPES pela bolsa de doutorado concedida a M. Martins através do Colegiado de Pós-graduação em Geologia da UFMG. Nossos sinceros agradecimentos aos revisores anônimos da RBG pelas valiosas críticas e sugestões que muito contribuíram para este artigo.

\section{Referências}

Alkmim F.F., Chemale Jr. F., Endo I. 1996. A deformação das coberturas Proterozóicas do Cráton do São Franciso e o seu significado tectônico. Revista da Escola de Minas, 49:22-38.

Alkmim F.F., Marshak S., Fonseca M.A. 2001. Assembling West Gondwana in the Neoproterozoic: clues from São Francisco Craton region, Brazil. Geology, 29:319-322.

Alkmim F.F., Marshak S., Pedrosa-Soares A.C., Peres G.G., Cruz S.C.P., Whittington A. 2006. Kinematic evolution of the Araçuaí-West Congo tectonics during Neoproterozoic assembly of Gondwana. Precambrian Research, 147:43-64.

Almeida F.F.M. 1977. O Cráton do São Francisco. Reista Brasileira de Geociências, 7:349-364.

Babinski M., Gradim R.J., Pedrosa-Soares A.C., Alkmim F.F., Noce C.M., Liu D. 2005. Geocronologia U-Pb (SHRIMP) e Sm-Nd de xistos verdes basálticos do Orógeno Araçuaí: implicações para a idade do Grupo Macaúbas. Revista Brasileira de Geociências, 35 (4-suplemento):77-81.

Babinski M., Pedreira A., Brito-Neves B.B., Van Schmus W.R. 1999. Contribuição à geocronologia da Chapada Diamantina. In: SBG, Simp. Nac. Est. Tect., 7, Atas, p. 118-120.

Babinski, M., Pedrosa-Soares, A.C., Martins M., Liu D., Noce C.M., Karfunkel J. 2007. Geocronologia U-Pb SHRIMP em zircões detríticos do Grupo Macaúbas: implicações na idade de deposição e proveniência dos sedimentos. In: Simpósio de Geologia do Sudeste, 10, Diamantina, MG. Programação e Livro de Resumos, p. 33.
Buchwaldt R., Toulkeridis T., Babinski M., Santos R., Noce C.M., Martins-Neto M., Hercos C. 1999. Age determination and age related provenance analysis of the Proterozoic glaciation event in central eastern Brazil. In: South Amer. Symp. Isotope Geol., Short Papers, p. 387-390.

Compston W., Williams I.S., Kirschvnik J.L. 1992. Zircon $\mathrm{U}-\mathrm{Pb}$ ages of early Cambrian timescale. J. Geol. Soc. 149:171-184.

Danderfer A. \& Dardenne M.A. 2002. Tectonoestratigrafia da Bacia Espinhaço na porção centro-norte do Cráton do São Francisco: registro de uma evolução poliistórica descontínua. Revista Bras. de Geociências, 32:449-460.

Dussin I.A. \& Dussin T.M. 1995. Supergrupo Espinhaço: modelo de evolução geodinâmica. Geonomos, 1:19-26.

Gradim R.J., Alkmim F.F., Pedrosa-Soares A.C., Babinski M., Noce C.M. 2005. Xistos verdes do Alto Araçuaí, Minas Gerais: vulcanismo básico do rifte Neoproterozoico Macaúbas. Revista Bras. de Geociências, 35:59-69.

Grossi-Sad J.H., Lobato L.M., Pedrosa-Soares A.C., SoaresFilho B.S. 1997. Projeto Espinhaço em CD-Rom. Belo Horizonte, COMIG, 2693p.

Karfunkel J. \& Hoppe A. 1988. Late Proterozoic Glaciation in Central-East Brazil: Synthesis and model. Palaeogeogaphy, Palaeoclimatologu, Palaeoecology, 65:1-21.

Karfunkel B. \& Karfunkel J. 1977. Fazielle entwicklung der mittleren Espinhaço-zone mit besonderer Brücksichtigung des tillit-problems. Geoogisches Jarbuch, Beihefte, 24:3-91.

Ludwig K.R. 2001. Squid 1.02: a user manual. Berkeley Geochronological Center Special Publication, 12:19. 
Machado N., Schrank A., Abreu F.R., Knauer L.G., AlmeidaAbreu P.A. 1989. Resultados preliminares da geocronologia U-Pb na Serra do Espinhaço Meridional, In: SBG, Simp. Geol. MG, 5, Anais, p. 171- 174.

Martins M.S. 2006. Geologia dos diamantes e carbonados aluvionares da bacia do Rio Macaúbas (MG). Tese de doutoramento, IGC, Univ. Federal Minas Gerais, 248p.

Martins-Neto M.A. 1998. O Supergrupo Espinhaço em Minas Gerais: registro de uma bacia rift-sag do Paleo/Mesoproterozoico. Revista Bras. de Geociências, 28:151-168.

Martins-Neto M.A. 2007. Sequence stratigraphic framework of Proterozoic successions in eastern Brazil. Marine and Petroleum Geology, doi:10.1016/j. marpetgeo.2007.10.001

Martins-Neto M.A. \& Alkmim F.F. 2001. Estratigrafia e evolução tectônica das bacias Neoproterozóicas do Paleocontinente São Francisco e suas margens: registro da quebra de Rodínia e colagem de Gondwana. In: Pinto C.P. \& Martins Neto M.A. (eds.) Bacia do São Francisco: geologia e recursos minerais. SBG-MG, p. 31-54.

Moraes L.J. 1928. Geologia da região diamantina de Minas Gerais - Relatório de atividades. Rio de Janeiro, DNPM, Serv. Geol. Min. Rel. Ann. Dir. 1928, p.29-34.

Moraes L.J. 1932. Área ocupada pela Formação Macahúbas no norte de Minas Gerais. Ann. Acad. Bras. Sci., 4:111114.

Moraes L.J. \& Guimarães D. 1930. Geologia da região diamantífera do Norte de Minas Gerais - An. Acad. Bras. Cienc., 2:153-186.

Moraes L.J., Barbosa O., Lisboa J.M.A., Lacourt F., Guimarães D. 1937. Geologia Econômica do Norte de Minas Gerais. R.de Janeiro, Boletim DNPM/SFPM 19, 191p.

Noce C.M. 1997. Texto explicativo da Folha Itacambira. In: Grossi-Sad J.H., Lobato L.M., Pedrosa-Soares A.C., Soares Filho B.S. (eds.) Projeto Espinhaço em CD-Rom. COMIG-UFMG.

Noce C.M., Pedrosa-Soares A.C., Grossi Sad J.H., Baars F.J., Guimarães M.L.V., Mourão M.A.A., Oliveira M.J.R., Roque N.C. 1993. Nova divisão estratigráfica regional do Grupo Macaúbas na Faixa Araçuaí: o registro de uma bacia neoproterozóica. Boletim do Núcleo Minas GeraisSociedade Brasileira de Geologia, 14:29-31.

Noce C.M., Silva L.C., Pedrosa-Soares A.C., Alkmim F.F., Peres G.G. 2003. O embasamento da Faixa Araçuaí no Bloco Guanhães: Dados geocronológicos e evolução. In: SBG, Simp. Geol. MG, 12, Anais, p. 90.

Pedrosa-Soares A.C., Vidal P., Leonardos O.H., Brito-Neves B.B. 1998. Neoproterozoic oceanic remnants in eastern Brazil: further evidence and refutation of an exclusively ensialic evolution for the Araçuaí-West Congo orogen. Geology, 26:519-522.

Pedrosa-Soares A.C., Noce C.M., Wiedemann-Leonardos C.M., Pinto C.P. 2001. The Araçuaí-West Congo orogen in Brazil: an overview of a confined orogen formed during Gondwana assembly. Precambrian Research, 110:307-323.

Petri S., Coimbra A.M., Amaral G., Ojeda H.O., Fúlfaro V.J., Ponçano W.P. 1986. Código Brasileiro de nomenclatura estratigráfica. Revista Brasileira de Geociências, 16:372-376.
Pinto C.P., Silva L.C., Leite C.A. 2003. Mapa Geológico do Estado de Minas Gerais, 1:1.000.000. Belo Horizonte, CPRM-CODEMIG, CD-ROM.

Queiroga G.N., Pedrosa-Soares A.C., Noce C.M., Alkmim F.F., Pimentel M.M., Dantas E., Martins M., Castañeda C., Suita M.T.F., Prichard H. 2007. Age of Ribeirão da Folha ophiolite, Araçuaí Orogen: the U-Pb zircon (LAICPMS) dating of a plagiogranite. Geonomos, 15(1):6165.

Salvador A. 1994. Lithostratigraphic units. In: Salvador A. (ed.) International Stratigraphic Guide. A guide to stratigraphic classification, terminology and procedure. Geological Society of America (International Subcomission on Stratigraphic Classification of International Union of Geological Sciences - IUGS; International Comission on Stratigraphy), 214p.

Silva L.C., Armstrong R., Noce C.M., Carneiro M.A., Pimentel M., Pedrosa-Soares A.C., Leite C.A., Vieira V.S., Silva M.A., Paes V.J.C., Filho J.M.C. 2002. Reavaliação da evolução geológica em terrenos pré-cambrianos brasileiros com base em novos dados U-Pb SHRIMP, parte II: Orógeno Araçuaí, Cinturão Mineiro e Cráton do São Francisco Meridional. Rev. Bras. Geoc., 32(4):513-528.

Tack L., Liégeois J.P., Deblond A., Duchesne J.C. 1994. Kibaran A-type granitoids and mafic rocks generated by two mantle sources in a late orogenic setting (Burundi). Precambrian Research, 68:323-356.

Tack L., Wingate M.T.D., Liègeois J.P., Fernandez-Alonso M., Deblond A. 2001. Early Neoproterozoic magmatism (1000-910 Ma) of the Zadinian and Mayumbian Groups (Bas-Congo): onset of Rodinia rifting at the western edge of the Congo Craton. Precambrian Research, 110:277306.

Uhlein A. 1991. Transição Cráton-Faixa Araçuai (Ciclo Brasiliano) no estado de Minas Gerais. Aspectos estratigráficos e estruturais. Tese de Doutoramento, Universidade de São Paulo, 259 p.

Uhlein A., Trompette R., Egydio-Silva M.E. 1995. Proterozoic rifting and closure, SE border of the São Francisco Craton, Brazil. Journal of South America Earth Science, 11:191-203.

Uhlein A., Trompette R.R., Alvarenga C.J.S. 1999. Neoproterozoic glacial and gravitacional sedimentation on a continental rifted margin: the Jequitaí-Macaúbas sequence (Minas Gerais, Brazil). Journal of South America Earth Science, 4-5/2:1-7.

Uhlein A., Alvarenga C.J.S., Trompette R., Dupont H., Egydio-Silva M., Cukrov N., Lima O.N.B. 2004. Glaciação Neoproterozóica sobre o Cráton do São Francisco e faixas dobradas adjacentes. In: Mantesso Neto V., Bartorelli A., Dal Ré Carneiro C., Brito-Neves B. (eds.) Geologia do Continente Sul-Americano: evolução da obra de Fernando Flávio Marques Almeida. São Paulo; Editora Beca, p. 539-553.

Manuscrito ID 11942 Submetido em 31 de julho de 2008 Aceito em 22 de dezembro de 2008 Sistema eletrônico de submissão 